\title{
A importância da guarda responsável de gatos domésticos: aspectos práticos e conexões com 0 bem-estar animal
}

\section{The importance of responsible cat ownership: practical aspects and connections with animal welfare}

\author{
Daiana de Souza Machado ${ }^{1}$, Juliana Clemente Machado², José Olimpio Tavares de Souza ${ }^{3}$, Aline Cristina Sant'Anna (D) ${ }^{4 *}$ \\ ${ }^{1}$ Programa de Pós-Graduação em Comportamento e Biologia Animal, Universidade Federal de Juiz de Fora (UFJF), Juiz de Fora, MG \\ ${ }^{2}$ Faculdade do Sudeste Mineiro (FACSUM), Juiz de Fora, MG, Brasil \\ ${ }^{3}$ Universidade Presidente Antônio Carlos (UNIPAC)/Zoovet Oftalmologia, Juiz de Fora, MG, Brasil \\ ${ }^{4}$ Universidade Federal de Juiz de Fora (UFJF), Juiz de Fora, MG
}

\section{Resumo}

A permissão do livre acesso à rua e outros ambientes externos aos gatos domésticos (Felis silvestris catus) por seus tutores pode gerar muitos problemas. Os transtornos causados pela presença destes animais vão desde impactos à fauna local das regiões com populações de gatos ferais e semi-domiciliados, até a disseminação de doenças. Gatos que não possuem áreas de vida delimitadas por seus tutores estão suscetíveis a sofrerem maus-tratos, contrair e disseminar patógenos e parasitos, sendo muitas das doenças veículadas por eles tidas como zoonoses. 0 objetivo deste trabalho, portanto, foi oferecer elementos e informações que embasem uma reflexão acerca da importância de um manejo apropriado do gato doméstico. Um método eficaz para solucionar os problemas associados ao livre acesso dos gatos à rua é a delimitação do espaço usado pelos mesmos. Animais que permanecem dentro de casa, em geral, estão seguros e com potencial de apresentar níveis adequados de bemestar, além de não causarem impactos à fauna silvestre nem ao bem-estar de outros animais domésticos.

Palavras-chave: Abandono. Comportamento animal. Felis silvestris catus. Zoonoses.

\begin{abstract}
Many problems can arise when domestic cats (Felis silvestris catus) have free access to the streets. The hazards caused by these cats range from impacts on the local fauna to the spreading of diseases. Cats that do not have set boundaries by their owners are more likely to suffer mistreatment,
\end{abstract}


contracting and spreading pathogens and parasites, many of them regarded as zoonotic diseases. Therefore, the objective of this review article was to provide precise information that raises the reader's awareness about the importance of appropriate management of domestic cats. An effective method to solve the problems associated with cats that are allowed to roam free is the setting of boundaries of the space used by these cats, since animals that remain indoors are generally safer with potential to have good levels of welfare and are less prone to harm other species.

Keywords: Abandonment. Animal behavior. Felis silvestris catus. Zoonoses.

\section{Introdução}

Registros arqueológicos e informações genéticas sugerem que a domesticação do gato (Felis silvestris catus Linnaeus, 1758) ocorreu há pelo menos 10 mil anos, a partir da subespécie conhecida como gato silvestre africano (Felis silvestris lybica), no Oriente Médio, região da crescente fértil (Vigne et al., 2004; Driscoll et al., 2007, 2009a). Esse processo se iniciou concomitantemente com o surgimento da agricultura, a partir de uma relação de comensalismo, na qual os gatos eram atraídos para locais próximos do ambiente antrópico pela disponibilidade de alimento, em especial de roedores associados aos excedentes de alimentos estocados pelo homem (Hu et al., 2014).

A partir deste momento, teve origem uma relação considerada mutualística do ser humano com o gato doméstico, visto que os gatos predavam os roedores, controlando sua proliferação e, em troca, o homem lhe oferecia abrigo e alimento (Driscoll et al., 2009a, b). A partir do Oriente Médio, a espécie se expandiu por todo o Velho Mundo através das rotas terrestres e marítimas de comércio durante a antiguidade clássica (Ottoni et al., 2017).

Desde então, o convívio com as pessoas tornouse cada vez mais íntimo e o gato doméstico vem ganhando popularidade em muitos lugares do mundo, como Japão, Estados Unidos e países da Europa (Driscoll et al., 2009a; Rehnberg et al., 2015; Seo e Tanida, 2017). No Brasil, o número de cães como animais de companhia ainda supera o número de gatos, entretanto, a preferência pelo gato vem aumentando significativamente nos últimos anos (Abinpet, 2018).

Com o aumento do número de gatos mantidos como animais de companhia, passa a ser também crescente a preocupação a respeito de seu bemestar (Ellis, 2009; Sparkes et al., 2013; Strickler e Shull, 2014; Amat et al., 2016; Stella e Croney, 2016; Gilhofer et al., 2019). Bem-estar é um tema de caráter multidisciplinar que engloba várias áreas do conhecimento, como etologia, fisiologia, psicologia, saúde e reprodução (Veissier e Miele, 2014). Conforme proposto por Broom (1986), temos como definição de bem-estar: "o estado físico e psicológico de um indivíduo em relação às suas tentativas de se adaptar ao meio em que vive". Assim, o bem-estar dos animais pode variar de muito bom a muito ruim.

Os principais problemas, ou pontos críticos, de bem-estar em gatos domésticos podem diferir em função do tipo de manejo e do modo de criação empregado (Jongman, 2007; Gibson et al., 2018). De acordo com a classificação proposta por Crowley et al. (2019), o modo de criação dos gatos pode ser: a) exclusivamente domiciliado (indoor), sendo os gatos mantidos totalmente confinados, com amplo controle de sua alimentação, reprodução e movimentação pelo tutor; b) domiciliados dentro e fora da residência (indoor - outdoor), são gatos também confinados mas com acesso à área externa da casa, isto é, com acesso a varandas e quintais, estando sujeitos ao controle de sua alimentação pelo tutor, porém, em menor grau, da reprodução e dos seus deslocamentos; c) não-confinados (freeranging): gatos que possuem domicílio, porém, têm acesso irrestrito à rua, com baixo controle de sua alimentação, reprodução e sem qualquer controle dos deslocamentos do animal pelo tutor; o gato pode entrar e sair livremente da casa e circular por uma ampla área de vida; d) gatos ferais (feral): sem nenhum grau de controle ou provisão por um tutor quanto à alimentação, reprodução ou deslocamento (Crowley et al., 2019). Assim, gatos na primeira e segunda condição (animais confinados) podem ser também chamados de animais domiciliados; gatos não confinados, com acesso livre à rua e provisão parcial, como semidomiciliados; e gatos na terceira condição (feral) podem também ser referidos como não domiciliados. 
Em nenhuma dessas condições de manejo é possível garantir que não ocorram pontos críticos de bem-estar, que possam implicar em algum tipo de risco à qualidade de vida dos animais (Yeates e Yates, 2017; Gibson et al., 2018). Em ambientes totalmente confinados, por exemplo, os gatos podem ter seus níveis de bem-estar comprometidos em função do tipo de interação humano-animal estabelecida com os tutores, as quais podem acarretar em medo e ansiedade (Strickler e Shull, 2014; Heath, 2019); limitação de espaço, ambientes monótonos e previsíveis, redução da possibilidade de expressar comportamentos naturais (Loberg e Lundmark, 2016); interações agonísticas com coespecíficos (em casas com múltiplos gatos) (Ramos, 2019), além de outros fatores potencialmente estressantes relacionados à restrição comportamental (Jongman, 2007; Rehnberg et al., 2015; Amat et al., 2016; Yeates e Yates, 2017).

Outros problemas que podem acometer os gatos confinados incluem a obesidade e os acidentes domésticos (Buffington, 2002; Rochlitz, 2005). Todos esses fatores merecem atenção e precaução, visando a manutenção de um ambiente propício a satisfazer as demandas dos gatos como, por exemplo, investindo-se no espaço físico com o uso de métodos de enriquecimento ambiental a fim de tornar o ambiente menos previsível, bem como reduzir o distresse e estimular a exibição de comportamentos naturais (Ellis, 2009; Strickler e Shull, 2014).

Por sua vez, os gatos semidomiciliados e ferais podem também enfrentar riscos e problemas de bem-estar, dependendo das condições ambientais em que vivem (Gilhofer et al., 2019). Estes podem sofrer com manejo nutricional inadequado e subnutrição, maus-tratos, morte por envenenamento, atropelamento, injúrias provocadas por outras espécies (como cães), lesões por brigas com outros gatos, maior risco de contração de doenças infectocontagiosas, entre outros (Buffington, 2002; Rochlitz, 2005; Marlet e Maiorka, 2010; Gilhofer et al., 2019). Outro ponto a ser considerado são os riscos para a fauna silvestre por meio da competição interespecífica, sobreposição de nicho ecológico, risco de predação e transmissão de doenças (VanWormer et al., 2013; Wald e Jacobson, 2013; Ferreira et al., 2014, 2018).
Deste modo, érelevante que se reúnam evidências científicas que permitam identificar os pontos críticos de bem-estar dos gatos nos mais diversos tipos de criação e condições de manejo, visando promover a melhoria de sua qualidade de vida. Assim, a presente revisão de literatura tem como objetivo apresentar informações quanto aos riscos ao bem-estar de gatos criados em condições semi ou não domiciliadas. Serão discutidos potenciais problemas relacionados à qualidade de vida do animal, à saúde pública e preservação da fauna silvestre, especificamente para gatos que tenham livre acesso à rua. Este texto não irá estabelecer uma abordagem comparativa quanto ao que é melhor em termos de bem-estar, confinamento vs. livre acesso ao exterior, visando não adentrar no complexo dilema indoor vs. outdoor (Yeates e Yates, 2017). Assim, a presente revisão irá levantar os potenciais problemas que podem advir do livre acesso dos gatos ao exterior, permitindo embasar futuras pesquisas e ações de conscientização para a posse responsável de animais de companhia.

\section{Riscos ao bem-estar dos gatos associados ao acesso à rua}

\section{Transmissão de doenças}

Os gatos com acesso irrestrito a ambientes diversos podem atuar como vetores de doenças ao entrarem em contato com outros animais (Patronek et al., 1996; Buffington, 2002; Rochlitz, 2005). 0 contágio dessas doenças se dá por transmissão horizontal, ocorrendo entre indivíduos de mesma espécie ou não, por contato com fezes e urina contaminadas, via aérea, via oral (por contato direto através de lambidas ou mordidas), por fômites (objetos inanimados contaminados), por vetores e por via ambiental. Dessa forma, os gatos podem levar doenças também a populações de felídeos silvestres, e o contrário também pode acontecer, com gatos domésticos podendo adquirir patógenos de animais silvestres (VanWormer et al., 2013; Carver et al., 2016).

Fatores como sexo, idade, estilo de vida, temperamento e condições físicas e/ou genéticas do animal podem afetar a prevalência de certas doenças 
que acometem os felinos (Buffington, 2002). Gatos machos adultos, não castrados e que possuem livre acesso à rua, estão mais susceptíveis a contraírem doenças infectocontagiosas, já que frequentemente brigam com outros gatos por recursos e realizam mais cópulas do que aqueles animais que tiveram seus testículos removidos cirurgicamente (Levy et al., 2006; Zanzani et al., 2014; Machado et al., 2018).

\section{Doenças infecciosas felinas}

As infecções virais, por exemplo, são doenças sistêmicas, imunomediadas, de prognóstico ruim e vitalício, com grande impacto na saúde e no bemestar dos gatos infectados (Rochlitz, 2005; Sturgess, 2007). Algumas das doenças causadas por essas infecções são típicas da família Felidae como, por exemplo, peritonite infeciosa felina (PIF), vírus da leucemia felina (FeLV) e vírus da imunodeficiência felina (FIV). É importante ressaltar que tais patologias se fazem presentes em felinos domésticos do mundo inteiro e também em muitos grupos de felídeos selvagens, sendo difícil predizer o número de indivíduos infectados, visto que os exames diagnósticos são voluntários e possuem testes específicos (Lutz, 1990; Sturgess, 2007).

A FeLV é uma doença que causa viremia persistente. Em geral, os indivíduos infectados podem apresentar quadros de imunossupressão, disfunção hematológica e hematopoética, desordens neoplásicas e degenerativas (Hagiwara et al., 2007). Uma pesquisa realizada nos Estados Unidos comparou a média de vida de mais de 1000 gatos infectados com FeLV com mais de 8000 gatos não infectados e descobriu que nos animais positivos a sobrevida média era de 2,4 anos em comparação com 6,0 anos para gatos do grupo controle (animais negativos) (Levy et al., 2006). Esse vírus é transmitido de um gato para outro, através da saliva (principal via), secreções nasais e lacrimais, leite, urina e fezes de gatos portadores e também por contato sexual. Há uma discussão de que pulgas também possam transmitir FeLV, uma vez que o RNA do vírus foi encontrado em fezes desses parasitas (Lutz, 1990; Levy et al., 2007).

Com relação à FIV, outro estudo realizado na América do Norte com mais de 18038 gatos verificou que $2,5 \%$ dos animais eram positivos.
A prevalência foi maior em gatos testados em clínicas veterinárias do que em abrigos de animais abandonados. Essa pesquisa verificou que os gatos que possuíam acesso à rua e os machos adultos e não castrados estão mais sujeitos a contraírem FIV, visto que a beligerância dentro do grupo é maior e, como já mencionado, tal vírus é comumente transmitido através de mordeduras e arranhadura (Levy et al., 2006).

Outras doenças também virais, e não menos prevalentes, são as do trato respiratório superior. Tais doenças são qualificadas por sintomas de corrimento nasal, espirros, conjuntivite, lacrimejamento, salivação e/ou ulcerações orais. Os agentes etiológicos principais são os herpesvírus felino do tipo 1 (FHV-1) e o calicivírus felino (FCV). Ambos os agentes também são específicos da família Felidae e não causam risco conhecido às pessoas (Radford et al., 2009).

Além dos vírus, há também outros agentes infecciosos, como é o caso das bactérias Bordetella bronchiseptica e Mycoplasma spp., podendo também causar sinais similares aos da doença respiratória. Acredita-se, porém, que em torno de $80 \%$ dos casos de problemas respiratórios em gatos domésticos sejam causados pelos FHV-1 e FCV, ou pela infecção dupla com esses dois agentes. Por exemplo, em um estudo utilizando amostras obtidas de gatos aparentemente saudáveis em uma exposição de gatos de raça, verificou-se que aproximadamente $30 \%$ dos gatos com menos de 1 ano de idade foram positivos para o calicivírus felino e $1 \%$ positivo para o vírus da rinotraqueíte felina (FHV-1) (Sturgess, 2007).

Em um estudo realizado no Japão sobre bem-estar de gatos de rua ao longo de três anos, verificou-se que aproximadamente $80 \%$ dos gatos encontrados no começo do estudo desapareceram até o terceiro ano. Devido à dificuldade de migração nas áreas da pesquisa, os autores sugerem que a causa mais provável para o desaparecimento dos gatos estudados seja a morte por doenças infecciosas e lesões por brigas (Seo e Tanida, 2017). Portanto, conforme verificado nas pesquisas citadas nessa revisão, os gatos com livre acesso à rua possuem baixa expectativa de vida devido ao alto risco de contraírem doenças infecciosas graves. 


\section{Zoonoses}

Ainda sobre doenças, há também aquelas que são zoonoses, isto é, doenças infecciosas que acometem os animais, mas que também podem ser naturalmente transmitidas ao homem. Diversos agentes etiológicos desencadeiam essas doenças, como bactérias, fungos, vírus, helmintos e protozoários (Rodrigues et al., 2018). A esporotricose, por exemplo, é uma doença infectocontagiosa que afeta gatos e seres humanos, causada por fungos do gênero Sporothrix. No caso dos gatos, esses fungos provocam lesões cutâneas que ulceram e liberam secreção seropurulenta, geralmente na região da cabeça, sobretudo no focinho e orelhas (Barros et al., 2010). A transmissão se dá pela inserção do fungo na pele, com sua entrada por um local onde haja ferimento prévio. A transmissão zoonótica aos seres humanos pode ocorrer pelo contato das secreções e lesões dos gatos com locais onde a pele da pessoa esteja ferida, além de mordeduras e arranhaduras pelos gatos infectados (Santos et al., 2018).

No Brasil, os casos de esporotricose em pessoas surgiram na década de 80 e, recentemente, vêm apresentando aumento, sobretudo no estado do Rio de Janeiro, cuja primeira epidemia registrada foi em 1998 (Barros et al., 2010). Nesse estado, a doença tem como principais características a ocorrência em áreas urbanas, com transmissão zoonótica em ambiente domiciliar, tendo como transmissor o gato (Silva et al., 2012). Após um aumento considerável nos casos de esporotricose em pessoas entre os anos de 1998 e 2015, em algumas localidades do país (como os estados do Rio de Janeiro e Pernambuco, bem como na cidade de Guarulhos), a notificação compulsória da doença tornou-se obrigatória (Rodrigues et al., 2018).

Em uma pesquisa realizada em Campos dos Goytacazes, RJ, verificou-se que do total de 100 gatos analisados, $66(66 \%)$ eram positivos para o Sporothrix spp., sendo que $46(69,6 \%)$ eram machos não castrados e 15 (22,7\%) eram fêmeas não castradas. Destes 100 indivíduos, 89,3\% tinham acesso à rua (Almeida et al., 2018). Dentre outros fatores, o livre acesso à rua, a criação em condição semidomiciliada e a não castração podem estar associados ao aumento do risco de gatos contraírem e disseminarem a doença (Santos et al., 2018).
A toxoplasmose também é uma zoonose, porém causada pelo protozoário Toxoplasma gondii. Esse parasito é comum em locais onde há gatos, visto que são seus hospedeiros definitivos, assim como os felinos selvagens, sendo a família Felidae a única que permite ao parasito completar sua fase sexuada. No entanto há uma ampla gama de hospedeiros intermediários, incluindo os seres humanos (Hill et al., 2005).

No Brasil, diversos estudos buscaram levantar a prevalência de toxoplasmose em gatos domésticos em diferentes municípios ou localidades. Nos municípios paranaenses de Cascavel e Palotina, por exemplo, foram reportadas prevalências de anticorpos anti-T. gondii de 28\% (Andrade et al., 2015) e 29\% (Souza et al., 2017), respectivamente, em gatos atendidos em consultas veterinárias. Por sua vez, uma menor prevalência $(16,3 \%)$ foi reportada na capital Curitiba (Cruz et al., 2011). A condição de criação dos gatos, predominantemente domiciliados e com elevada porcentagem de animais castrados na amostragem em questão, foi um dos fatores levantados pelos autores para explicar a menor prevalência na capital.

A infecção em pessoas pode acontecer pela ingestão dos oocistos liberados nas fezes dos animais infectados (via fecal-oral), pelo consumo de carne infectada (ingestão dos cistos presentes em tecidos de hospedeiros intermediários) e pela via transplacentária (transmissão vertical) (Hill et al., 2005).

A infecção por T. gondii em seres humanos é frequentemente assintomática e, quando acarreta quadros clínicos, os sintomas mais comuns são anorexia, febre, letargia, dispneia, icterícia, dores musculares, pancreatite e, às vezes, sinais neurológicos. Também possui forte impacto na saúde de neonatos, caso a mãe adquira o parasito durante a gravidez, podendo causar lesões oculares, hidrocefalia, microcefalia, calcificações cerebrais, deficiência intelectual e alterações psicomotoras (Souza et al., 2017). No Brasil, a soroprevalência de T. gondii em humanos é alta, tanto na população em geral (variando de $21,5 \%$ a $97,4 \%$ ), quanto em mulheres gestantes (de 36,8\% a 92,0\%), com a maioria dos trabalhos reportando prevalências acima de $50 \%$ nas populações amostradas, conforme um amplo levantamento bibliográfico realizado por 
Dubey et al. (2012). Segundo estimativa apresentada por esses autores, a cada ano 2649 bebês nascem infectados com toxoplasmose congênita no Brasil. Parte deles morre após o nascimento e, dentre os que sobrevivem, $35 \%$ apresentam sequelas neurológicas, $80 \%$ apresentam lesões oculares e $40 \%$ têm perda auditiva (Dubey et al., 2012).

Desta forma, medidas profiláticas e de cuidados com os gatos baseadas na guarda responsável são eficazes para a prevenção da toxoplasmose, tanto nas pessoas quanto nos próprios gatos. As medidas de prevenção a serem adotadas para evitar a contaminação nos gatos são: limpeza diária da caixa de areia e do ambiente onde vive o animal, restrição do acesso do animal a ambientes externos (a fim de prevenir a predação de presas infectadas por T. gondii e o contágio por contato indireto com outros gatos) e evitar alimentar os gatos com carne crua (Galvão et al., 2018). Em relação à prevenção da toxoplasmose em humanos, os cuidados profiláticos incluem: cuidados ao descartar as fezes dos gatos, evitando entrar em contato com as mesmas e a contaminação do ambiente e dos alimentos (como em hortas), lavar mãos antes de manipular alimentos, evitar ingerir carnes cruas ou mal passadas, lavar frutas, legumes e hortaliças antes de ingeri-los e beber apenas água filtrada (Galvão et al., 2018).

Outras doenças que podem ser adquiridas e veículadas por gatos que possuem acesso à rua são: raiva, giardíase, dipilidose, ancilostomose e toxocaríase. Com relação a esse último, em uma pesquisa realizada no norte da Itália para avaliar a prevalência, os riscos zoonóticos e a conscientização de donos de animais de estimação quanto a parasitos intestinais, verificou-se que os animais com acesso à rua estão mais susceptíveis ao contágio por Toxocara (Zanzani et al., 2014). Esses autores observaram diferenças significativas entre gatos com acesso à rua e gatos que vivem dentro de casa: $\mathrm{p}=50 \%$ para gatos sem acesso ao ambiente externo vs. $p=65,52 \%$ para gatos com acesso ao ambiente externo (Zanzani et al., 2014).

Alguns autores sugerem que o aumento de casos de zoonoses transmitidas por animais domésticos está associado, em geral, à grande quantidade de cães e gatos abandonados ou que não recebem tratamento adequado de seus donos, por meio da prevenção de doenças com vacinação e vermifugação (Loss et al., 2012; Oliveira-Neto et al., 2017; Rodrigues etal., 2018). Esse aumento também pode estar relacionado com a falta de conhecimento da população sobre o contágio de zoonoses (Matos et al., 2015; Pereira et al., 2016).

Algumas pesquisas avaliaram o nível de conhecimento de tutores de animais sobre as doenças que podem ser veículadas por eles. Em um estudo conduzido no município de Fernandópolis, interior do estado de São Paulo, no período de março a junho de 2017, foi reportada uma prevalente falta de conhecimento da população alvo $(\mathrm{n}=100)$ em relação às zoonoses que podem ser transmitidas por cães e gatos (Oliveira-Neto et al., 2017). Verificou-se, também, que a população amostrada não compreendia a importância da prevenção de doenças em seus animais, procurando auxílio de um médico veterinário apenas na presença de sinais clínicos. Um resultado semelhante foi obtido por Rodrigues et al. (2018), que também verificaram um baixo entendimento sobre zoonoses por parte dos tutores no município de Capão Redondo, também no estado de São Paulo.

As consequências do desconhecimento pela população em geral sobre as formas de contágio e medidas preventivas de zoonoses podem ser preocupantes. A falta de conhecimento pode elevar a exposição das pessoas aos agentes patogênicos, inclusive contribuindo para a ocorrência de epidemias, como vem acontecendo em algumas regiões do Brasil com o aumento expressivo dos casos de esporotricose (Tavares da Silva et al., 2012; Santos et al., 2018). Como parte das medidas preventivas para evitar a disseminação dessas doenças está a informação e conscientização dos tutores por parte dos médicos veterinários quando em consultas de rotina (Pfukenyi et al., 2010), além de outras ações que visem a educação e informação da população em geral como, por exemplo, a inserção de dinâmicas e projetos sobre posse responsável e zoonoses na educação básica em escolas (Cunha et al., 2016).

\section{Injúrias}

No Brasil, casos de maus-tratos com animais que possuem acesso à rua são cotidianamente noticiados, mesmo eles estando juridicamente protegidos 
desse tipo de ação, pois maltratar animais é crime previsto no artigo 32 da Lei de Crimes Ambientais (Brasil, 1998). Um levantamento realizado em São Paulo revelou que gatos são mais frequentemente alvos de crueldade, quando comparados aos cães, e que o método mais comumente utilizado é a intoxicação do animal por carbamatos (veneno conhecido como chumbinho). Tal estudo foi feito através da análise das fichas de necropsia e registros criminais de maus-tratos com animais (Marlet e Maiorka, 2010).

É possível inferir que as motivações que ocasionam casos de maus-tratos por parte de não tutores têm como justificativa o desgosto de algumas pessoas pelas visitas dos gatos em suas residências, prazer em maltratar animais apenas para obtenção de sensação de poder e/ou por transtornos mentais e de caráter (Lockwood, 2005). Uma pesquisa realizada com tutores de gatos no município de Itaperuna, RJ, durante uma campanha de vacinação, revelou que dos 48 tutores entrevistados, 33 $(68,75 \%)$ afirmaram que já tiveram gatos que, por algum motivo, não retornaram à residência (Nolêto et al., 2017).

Além das injúrias decorrentes de ações de maustratos, os gatos também podem ser lesionados por outras espécies como, por exemplo, sofrer mordeduras por cães (Shamir et al., 2002). Há também as brigas com coespecíficos como um importante fator de risco para ferimentos nos gatos. Estas interações agonísticas intraespecíficas ocorrem porque os gatos são animais territorialistas e, muitas vezes, demonstram comportamento hierárquico e de dominância. Assim, ao perceberem a "invasão" do seu espaço por outros gatos, por vezes podem reagir de modo agressivo, especialmente quando em contextos de defesa de recursos (Machado et al., 2018).

Nesse sentido, animais que não são castrados podem estar mais pré-dispostos a se envolverem em brigas. Como muitas das doenças mencionadas anteriormente são também contraídas através de arranhaduras ou mordeduras, acredita-se que animais com acesso à rua e não castrados estejam mais expostos à contaminação de algumas doenças (Levy et al., 2006).

Outra consequência proveniente de conflitos com coespecíficos são os abcessos. Brigas entre gatos podem causar lesões que, quando não tratadas de forma adequada, podem gerar sepse e levar o animal a óbito (Norsworthy, 2009). Abscessos são feridas comumente causadas por arranhadura e mordidas, que atingem a pele e tecido subcutâneo, causando uma lesão de pequeno diâmetro, porém, profunda. Por conseguinte, em pouco tempo a lesão na pele se fecha prendendo sujidades e bactérias ali presentes, causando infecções bacterianas. Assim, a ferida evolui para uma bolsa local com pus e forte odor (Norsworthy, 2009).

As injúrias também podem ser decorrentes de atropelamentos. Em função do acesso irrestrito à rua, os gatos podem ser até três vezes mais propensos a serem acidentados por carros do que os cães, segundo um estudo realizado na França (Moreau et al., 2003). Além disso, é comum que as injúrias causadas por esse tipo de acidente sejam fatais. Em um levantamento realizado no Reino Unido, com um universo amostral de 1264 animais, 3,4\% foram vítimas de acidentes de trânsito, sendo que $71,4 \%$ deles resultou em injúrias fatais, culminando na morte do gato (Wilson et al., 2017). Segundo os autores, o acesso do gato à rua foi o principal fator de risco associado aos atropelamentos, independentemente da cor, raça, sexo e castração (ou não) do gato.

Desse modo, é possível perceber a seriedade dos riscos associados ao livre acesso de gatos domésticos à rua, o que os torna suscetíveis a morrerem por atropelamento, envenenamento, ataques por cães e infecções causadas por outros tipos de lesões.

\section{Abandono}

O abandono é outra prática comum que possui impacto negativo na qualidade de vida de animais que, outrora, foram domiciliados. De um modo geral, o acesso dos gatos à rua pode predispor a algumas das circunstâncias relatadas em estudos prévios como fatores de risco ao abandono. Por exemplo, animais não castrados e que possuem acesso à rua, muitas vezes terão crias em lugares distantes de onde moram e estas, por sua vez, crescerão desprovidas de tutela (Patronek et al., 1996; Baquero et al., 2017). Outra situação de risco pode ocorrer quando os gatos adquirem doenças e/ ou parasitos e são abandonados por seus tutores, 
por esses equivocadamente considerarem essa prática mais viável do que o tratamento do animal. Em um estudo de opinião pública sobre a gestão populacional de cães e gatos realizado no município de Votorantim, SP, foi evidenciado que o abandono frequentemente é considerado como uma solução para problemas comportamentais dos gatos ou como o destino para animais indesejados como, por exemplo, as crias indesejadas (Baquero et al., 2017).

Patronek et al. (1996) sugerem como possíveis motivações para o abandono de gatos os problemas de saúde, agressividade, falta de vínculo emocional (apego) do tutor para com o animal, expectativa errada em relação ao comportamento do gato, bem como falta de conhecimento sobre o comportamento típico da espécie. Baquero et al. (2017) também identificaram como causas mais comuns para o abandono de animais as agressões realizadas pelos gatos, doenças e problemas comportamentais.

Em um estudo realizado para determinar a soroprevalência de dirofilariose em cães e soroprevalências de dirofilaríase, infecção por FeLV e infecção por FIV em gatos que foram removidos da área de desastre na Costa do Golfo após os furacões de 2005, foram verificados os seguintes fatores como possíveis causas para esses animais serem deixados para trás por seus tutores: posse de vários animais de estimação, falta de preparo, baixo apego aos animais de estimação e falta de cuidados veterinários prévios (Levy et al., 2007). Esse mesmo estudo verificou que dos 1286 animais avaliados, $34(2,6 \%)$ eram positivos para FeLV e $45(3,6 \%)$ para FIV.

\section{Crias indesejadas}

Gatas não castradas podem ter de duas até três gestações em um ano e cada gestação pode gerar de um a seis filhotes (Axnér, 2011; Zito et al., 2016). Assim, gatos abandonados ou com acesso à rua, que não são castrados, estão sujeitos a procriarem e, frequentemente, o resultado são gerações de gatos ferais. Por esta razão, a retirada de animais da rua após longo período nas mesmas é geralmente complicada em vista de um pobre processo de socialização (Downey e Ellis, 2008). A socialização com o ser humano é um processo de suma importância no desenvolvimento de qualquer animal de companhia, ocorrendo nos estágios iniciais da vida (Manteca, 2015). Esta possibilita ao animal mudanças de comportamento como resultado da convivência intra e interespecífica, bem como novos ambientes. Indivíduos corretamente socializados possuem melhores chances de serem beneficiados com adoções bem-sucedidas, enquanto as perspectivas são menores para aqueles que não tiveram oportunidade de socialização com o ser humano (Downey e Ellis, 2008).

Em muitos países, como nos EUA e no Japão, o resultado da proliferação de gatos na rua acaba levando à eutanásia. Os indivíduos abandonados são recolhidos das ruas e encaminhados a abrigos e, após um tempo nos mesmos, é realizada a eutanásia em cerca de $75 \%$ dos gatos que chegam aos abrigos (Seo e Tanida, 2017; Nunes e Soares, 2018). Em suma, crias indesejadas e sem tutela aumentam as populações de gatos abandonados e, consequentemente, todos os transtornos acarretados por eles, como prejuízos à fauna e à saúde pública (Gilhofer et al., 2019).

\section{Impactos sobre a fauna silvestre}

0 acesso do gato doméstico em ambientes naturais, fruto do abandono ou da permissão de seu livre acesso, pode gerar impacto à fauna silvestre, como já foi constatado por pesquisas conduzidas no Brasil (Campos et al., 2007; Lessa e Bergallo, 2012; Ferreira et al., 2014, 2018) e em outros locais do mundo, como Georgia (Loyd et al., 2013), Reino Unido (Bonnington et al., 2013; McDonald et al., 2015), Polônia (Krauze-Gryz et al., 2017) e Estados Unidos (Loss et al., 2013). Assim como seus ancestrais selvagens, os gatos domésticos apresentam um hábito natural de caça mantido ao longo da evolução e, ainda que bem alimentados, caçam, pois este é um comportamento inato e não possui estrita relação com a fome (McDonald et al., 2015). Desse modo, gatos foram considerados responsáveis por predar diversas espécies selvagens de invertebrados, herpetofauna, aves e pequenos mamíferos, inclusive algumas delas ameaçadas de extinção (Campos et al., 2007; Medina et al., 2011; Lessa e Bergallo, 2012; Bonnington et al., 2013; Ferreira et al., 2014, 2018; McDonald et al., 2015; Loss e Marra, 2017). 
Em uma revisão sistemática onde os autores levantaram dados sobre os impactos causados por gatos ao redor do mundo, evidenciou-se maior risco às espécies insulares e endêmicas (em especial de mamíferos), com impactos já reportados em 120 ilhas, colocando em risco 175 espécies (25 répteis, 123 aves e 27 de mamíferos) (Medina et al., 2011). Os autores sugerem que os gatos domésticos introduzidos em ambientes silvestres foram responsáveis por $14 \%$ das extinções de aves, mamíferos e répteis e são a principal ameaça a 8\% das espécies criticamente ameaçadas (Medina et al., 2011). De acordo com Loss e Marra (2017), anualmente os gatos domésticos causam a morte de aproximadamente 2,4 bilhões de aves nos Estados Unidos. Tal pesquisa se baseou na análise de dados de cerca de 90 publicações disponíveis na literatura científica.

Dentre os mamíferos, as preferências por presas pelos gatos variam entre os continentes (Bradshaw, 2012). Na América do Norte e Europa, roedores são mais comuns, porém, há também a predação de coelhos e lebres por estes serem maiores e, dessa forma, representarem um retorno energético maior (Bradshaw, 2012). Pode haver também variação no tipo de presa em função da área, com predomínio de aves em perímetro urbano, enquanto na zona rural predominam os roedores, pequenos mamíferos (como mussaranhos) e répteis (Krauze-Gryz et al., 2017), além de importantes variações sazonais.

Segundo Bonnington et al. (2013), gatos que vivem soltos em áreas onde existem ninhos de aves desencadeiam um efeito cascata que propicia a predação de, pelo menos, o dobro de ovos e filhotes por outros animais. Além de alterar o comportamento parental, diminuindo em até 33\% a quantidade de alimento que será oferecido à prole no ninho, a presença de gatos pode tornar os pais mais agressivos com vocalizações mais intensas, o que pode atrair predadores adicionais. Ocorre também a modificação do comportamento de algumas presas como estratégia de mitigar a predação, todavia essas modificações, chamadas de subletais, podem ter implicações consideráveis na dinâmica populacional e nas comunidades de animais silvestres (Bonnington et al., 2013).
Os gatos com frequência trazem os animais que abatem para a casa e, por vezes, não os ingerem. Mesmo quando estão bem alimentados e com suas demandas energéticas supridas, os gatos podem exibir comportamento predatório, fato este que evidencia o impacto que animais com livre acesso a áreas naturais podem causar (Bradshaw, 2007). Embora seja comum que o animal traga a presa para a residência e/ou a consuma, sabe-se que os gatos podem ferir ou até mesmo matar presas e deixá-las no campo (Krauze-Gryz et al., 2017).

Os impactos ecológicos realizados por gatos domésticosferais, errantes e semidomiciliadoslevou a União Internacional para Conservação da Natureza (IUCN) a incluí-los na lista global das 100 piores espécies invasoras (Lowe et al., 2000). A competição interespecífica por recursos (alimentos, territórios e parceiros) é um fator também preocupante, pois os gatos podem atuar sobrepondo o uso de recursos com outros animais que possuem nichos ecológicos semelhantes, não apenas mamíferos carnívoros, como também com determinadas espécies de aves de rapina e alguns répteis. Por fim, os impactos dos gatos à fauna silvestre podem ocorrer também pelo risco da transmissão de doenças, principalmente aos felídeos silvestres que vivem em sintropia com os animais domésticos (Bevins et al., 2012; Tortato et al., 2013; Carver et al., 2016), mas também a outras espécies da ordem Carnivora (VanWormer et al., 2013). Esse é um tipo de impacto ainda pouco estudado, com carência de levantamentos tanto no Brasil quanto em outros países.

\section{Conclusão}

Os gatos que possuem livre acesso à rua estão expostos a sofrerem acidentes e iniquidades, bem como a serem reservatórios de muitos patógenos, 0 que pode desencadear uma série de efeitos danosos para coespecíficos, para outras espécies animais, bem como para as pessoas. A guarda responsável é a melhor forma de reduzir os riscos ao bem-estar dos gatos domésticos e os problemas que seu livre acesso à rua pode ocasionar. Para isso, a redução da área de uso do gato e a conscientização de seus tutores são fundamentais. 


\section{Referências}

Abinpet: Associação Brasileira da Indústria de Produtos para Animais de Estimação. 2018 [acesso 18 março 2018]. Disponível em: http://abinpet.org.br/

Almeida AJ, Reis NF, Lourenço CS, Costa NQ, Bernardino ML, Vieira-da-Motta O. Sporotrichosis in domestic felines (Felis catus domesticus) in Campos dos Goytacazes/RJ, Brazil. Pesqui Vet Bras. 2018;38(7):1438-43.

Amat M, Camps T, Manteca X. Stress in owned cats: Behavioural changes and welfare implications. J Feline Med Surg. 2016;18(8):577-86.

Andrade ACS, Bittencour LHFB, Godoi NFC, Libardi KA, Weschenfelder DRS, Picolotto GCGP. Prevalência de anticorpos anti-Toxoplasma gondii em felinos frequentadores de clínicas e hospitais veterinários de Cascavel, Paraná, Brasil. Arq Cienc Vet Zool. 2015;18(4):221-4.

Axnér E. Desempenho e problemas reprodutivos. In: August JR. (E.). Medicina Interna de Felinos. Rio de Janeiro: Elsevier; 2011. p. 835.

Baquero OS, Chiozzotto EN, Garcia RCM, Amaku M, Ferreira F. Abandonment of dogs and cats: Public opinions as population management indicators. J Appl Anim Welf Sci. 2017;20(3):289-95.

Barros MBL, Schubach TP, Coll JO, Gremião ID, Wanke B, Schubach A. Esporotricose: a evolução e os desafios de uma epidemia. Rev Panam Salud Publica. 2010;27(6):455-60.

Bevins SN, Carver S, Boydston EE, Lyren LM, Alldredge M, Logan KA, et al. Three pathogens in sympatric populations of pumas, bobcats, and domestic cats: implications for infectious disease transmission. PLoS One. 2012;7(2): e31403.

Bonnington C, Gaston KJ, Evans KL. Fearing the feline: domestic cats reduce avian fecundity through traitmediated indirect effects that increase nest predation by other species. J Appl Ecol. 2013;50:15-24.
Brasil. Lei n‥ 9.605, de 12 de fevereiro de 1998. Dispõe sobre as sanções penais e administrativas derivadas de condutas e atividades lesivas ao meio ambiente, e dá outras providências [acesso 3 mar 2018]. Disponível em: https://tinyurl.com/bscgg2z

Broom DM. Indicators of poor welfare. $\mathrm{Br}$ Vet J. 1986;142(6):524-6.

Buffington CA. External and internal influences on disease risk in cats. J Am Vet Med Assoc. 2002; 220(7): 994-1002.

Campos CB, Esteves CF, Ferraz KMPMB, Crawshaw Jr,PG, Verdade LM. Diet of free-ranging cats and dogs in a suburban and rural environment, south-eastern Brazil. J Zool. 2007;273(1):14-20.

Carver S, Bevins SN, Lappin MR, Boydston EE, Lyren LM, Alldredge M, et al. Pathogen exposure varies widely among sympatric populations of wild and domestic felids across the United States. Ecol Appl. 2016;26(2): 367-81.

Crowley SL, Cecchetti M, McDonald RA. Hunting behaviour in domestic cats: An exploratory study of risk and responsibility among cat owners. People and Nature. 2019;1(1):18-30.

Cruz MA, Ullmann LS, Montaño PY, Hoffmann JL, Langoni H, Biondo AW. Soroprevalência de infecção anti-Toxoplasma gondii em gatos domésticos de Curitiba, Paraná, Brasil. Rev Bras Parasitol Vet. 2011;20(3):256-8.

Cunha GR, Martins CM, Pellizzaro M, Barros CC, Pampuch RS, Wouk, AFPF, et al. Responsible pet ownership perception in elementary schools after an educational program in Southern Brazil. Braz J Vet Res Anim Sci. 2016;53(2):182-90.

Downey H, Ellis S. Tails of animal attraction: Incorporating the feline into the family. J Bus Res. 2008;61(5):434-41.

Driscoll CA, Clutton-Brock J, Kitchener AC, O’Brien SJ. The taming of the cat. Genetic and archaeological findings hint that wildcats became housecats earlier and in a different place than previously thought. Sci Am. 2009a;300(6):68-75. 
Driscoll CA, Macdonald DW, O’Brien SJ. From wild animals to domestic pets, an evolutionary view of domestication. Proc Natl Acad Sci U S A. 2009b;106 (Suppl 1): 9971-8.

Driscoll CA, Menotti-Raymond M, Roca AL, Hupe K, Johnson WE, Geffen E, et al. The Near Eastern origin of cat domestication. Science. 2007;317(5837): 519-23.

Dubey JP, Lago EG, Gennari SM, Su C, Jones JL. Toxoplasmosis in humans and animals in Brazil: high prevalence, high burden of disease, and epidemiology. Parasitology. 2012;139(11):1375-424.

Ellis SLH. Environmental enrichment: practical strategies for improving feline welfare. J. Feline Med Surg. 2009;11(11):901-12.

Ferreira GA, Genaro G. Predation of birds by domestic cats on a Neotropical island. Int J Avian Wildlife Biol. 2017;2(2):60-3.

Ferreira GA, Nakano-Oliveira E, Andriolo A, Genaro G. Spatial overlap between domestic cats and wild felines in an insular Atlantic Forest remnant. Anim Biol Leiden Neth. 2018;69(2):157-72.

Ferreira GA, Nakano-Oliveira E, Genaro G. Domestic cat predation on Neotropical species in an insular Atlantic Forest remnant in southeastern Brazil. Wildlife Biology. 2014;20(3):167-75.

Galvão AL, Rosseto VJ, Cruz BC, Teixeira AJ, Bresciani KD. Congenital Toxoplasmosis in Cats. In: Bresciani KDS, Costa AJ (EE.). Congenital Toxoplasmosis in Humans and Domestic Animals. Sharjah, EAU: Bentham Science Publishers; 2018. p. 67-74.

Gibson E, Blackwell EJ, Roberts C, Gruffydd-Jones TJ, Murray JK, Williams J. Comparison of diseases and problematic behaviours in cats confined indoors or allowed outdoor access. BSAVA Congress Proceedings. $2018 ; 471$.

Gilhofer EM, Windschnurer I, Troxler J, Heizmann V. Welfare of feral cats and potential influencing factors. J VeT Behav. 2019;30:114-23.
Hagiwara MK, Reche Jr A, Lucas SRR. Estudo clínico da infecção de felinos pelo vírus da leucemia felina em São Paulo. Rev Bras Cienc Vet. 1997; 4(1):35-8.

Heath S. Common feline problem behaviours: Unacceptable indoor elimination. J Feline Med Surg. 2019;21(3):199-208.

Hill DE, Chirukandoth S, Dubey JP. Biology and epidemiology of Toxoplasma gondii in man and animals. Anim Health Res Rev. 2005;6(1):41-61.

Hu Y, Hu S, Wang W, Wu X, Marshall FB, Chen X, et al. Earliest evidence for commensal processes of cat domestication. Proc Natl Acad Sci U S A. 2014;111(1):116-20.

Jongman EC. Adaptation of domestic cats to confinement. J Vet Behav. 2007;2(6):193-6.

Krauze-Gryz D, Żmihorski M, Gryz J. Annual variation in prey composition of domestic cats in rural and urban environment. Urban Ecosyst. 2017;20(4):945-52.

Lessa ICM, Bergallo HG. Modelling the population control of the domestic cat: an example from an island in Brazil. Braz J Biol. 2012;72(3):445-52.

Levy JK, Edinboro CH, Glotfelty CS, Dingman PA, West AL, Kirkland-Cady KD. Seroprevalence of Dirofilaria immitis, feline leukemia virus, and feline immunodeficiency virus infection among dogs and cats exported from the 2005 Gulf Coast hurricane disaster area. J Am Vet Med Assoc. 2007;231(2):218-225.

Levy JK, Scott HM, Lachtara JL, Crawford PC. Seroprevalence of feline leukemia virus and feline immunodeficiency virus infection among cats in North America and risk factors for seropositivity. J Am Vet Med Assoc. 2006;228(3):371-6.

Loberg JM, Lundmark F. The effect of space on behaviour in large groups of domestic cats kept indoors. Appl Anim Behav Sci. 2016;182:23-9.

Lockwood R. Cruelty toward cats: Changing perspectives. In: Salem DJ, Rowan AN. The state of the animals III. Washington: Humane Society; 2005. p. 15-26. 
Loss LD, Mussi JMS, Mello INK, Leão MS, Franque MP. Posse responsável e conduta de proprietários de cães no Município de Alegre-ES. Acta Vet Brasilica. 2012;6(2):105-11.

Loss SR, Marra PP. Population impacts of free-ranging domestic cats on mainland vertebrates. Front Ecol Environ. 2017;15(9):502-9.

Loss SR, Will T, Marra PP. The impact of free-ranging domestic cats on wildlife of the United States. Nat. Commun. 2013;4:1396.

Lowe S, Browne M, Boudjelas S, Poorter M. 100 of the world's worst invasive alien species: a selection from the Global Invasive Species Database. Auckland: ISSG; 2000. $12 \mathrm{p}$.

Lutz H. Feline retroviruses: a brief review. Vet Microbiol. 1990;23(1-4):131-46.

Machado JC, Ferreira GA, Genaro G. Castração e BemEstar Felino. Rev Bras Zoociencias. 2018;19(2):265-79.

Manteca X. Etología clínica veterinaria del perro y del gato. Barcelona: Miltimédica; 2015.

Marlet EF, Maiorka PC. Análise retrospectiva de casos de maus tratos contra cães e gatos na cidade de São Paulo. Braz J Vet Res Anim Sci. 2010;47(5):385-94.

Matos M, Alho AM, Owen SP, Nunes T, Carvalho LM. Parasite control practices and public perception of parasitic diseases: a survey of dog and cat owners. Prev Vet Med. 2015;122(1-2):174-80.

McDonald JL, Maclean M, Evans MR, Hodgson DJ. Reconciling actual and perceived rates of predation by domestic cats. Ecol Evol. 2015;5(14):2745-53.

Medina FM, Bonnaud E, Vidal E, Tershy BR, Zavaleta ES, Donlan CJ, et al. A global review of the impacts of invasive cats on island endangered vertebrates. Glob Chang Biol. 2011;17(11):3503-10.

Moreau D, Cathelain P, Lacheretz A. Comparative study of causes of death and life expectancy in carnivorous pets (II). Rev Med Vet (Toulouse). 2003;154(2):127-32.
Nolêto FDFZ, Nolêto VAZ, Ribeiro MLC, Dias FRC, Silva DA. Perfil dos tutores de gatos e aspectos relacionados à sua criação. Acta Biomed Bras. 2017;8(1):84-94.

Norsworthy GD. Bite Wounds: Felines. In: Norsworthy GD, Grace SF, Crystal MA, Tilley LP (EE.). The feline patient. Ames: John Wiley \& Sons; 2011. p. 44-5.

Nunes VP, Soares GM. Gatos, equívocos e desconhecimento na destinação de animais em abrigos: Revisão da Literatura. Rev Bras Zoocienc. 2018;19(2):185-203.

Oliveira-Neto RR, Souza VF, Carvalho PFG, Frias DFR. Nível de conhecimento de tutores de cães e gatos sobre zoonoses. Rev Salud Publica. 2018;20(2):198-203.

Ottoni C, Van Neer W, Cupere B, Daligault J, Guimaraes S, Peters J, et al. The palaeogenetics of cat dispersal in the ancient world. Nat Ecol Evol. 2017;1(7):0139.

Patronek GJ, Glickman LT, Beck AM, McCabe GP, Ecker C. Risk factors for relinquishment of cats to an animal shelter. J Am Vet Med Assoc. 1996; 209(3):582-8.

Pereira A, Martins A, Brancal H, Vilhena H, Silva P, Pimenta $\mathrm{P}$, et al. Parasitic zoonoses associated with dogs and cats: a survey of Portuguese pet owners' awareness and deworming practices. Parasit Vectors. 2016;9(1):245.

Pfukenyi DM, Chipunga SL, Dinginya L, Matenga E. A survey of pet ownership, awareness and public knowledge of pet zoonoses with particular reference to roundworms and hookworms in Harare, Zimbabwe. Trop Anim Health Prod. 2010;42(2):247-52.

Radford AD, Addie D, Belák S, Boucraut-Baralon C, Egberink H, Frymus T, et al. Feline Calicivirus Infection: ABCD Guidelines on Prevention and Management. J Feline Med Surg. 2009;11(7):556-64.

Ramos D. Common feline problem behaviors: Aggression in multi-cat households. J Feline Med Surg. 2019;21(3):221-33.

Rehnberg LK, Robert KA, Watson SJ, Peters RA. The effects of social interaction and environmental enrichment on the space use, behaviour and stress of owned housecats facing a novel environment. Appl Anim Behav Sci. 2015;169:51-61. 
Rochlitz I. A review of the housing requirements of domestic cats (Felis silvestris catus) kept in the home. Appl Anim Behav Sci. 2005;93(1-2):97-109.

Rodrigues DKB, Müller EDV, Moraes MCL. Análise do conhecimento sobre zoonoses transmitidas por gatos. Multitemas. 2018;23(55):81-94.

Santos AF, Rocha BD, Valgas e Bastos C, Oliveira CSF, Soares DFM, Pais GCT. Guia Prático para enfrentamento da Esporotricose Felina em Minas Gerais. Rev V\&Z. 2018;38(137):16-27.

Seo A, Tanida H. Three-year route census study on welfare status of free-roaming cats in old-town Onomichi, Japan. J Appl Anim Welf Sci. 2018;21(3):203-10.

Shamir MH, Leisner S, Klement E, Gonen E, Johnston DE. Dog bite wounds in dogs and cats: a retrospective study of 196 cases. J Vet Med A Physiol Pathol Clin Med. 2002;49(2):107-12.

Silva MBT, Costa MMM, Torres CCS, Galhardo MCG, Valle ACF, Magalhães MAFM, et al. Esporotricose urbana: epidemia negligenciada no Rio de Janeiro, Brasil. Cad Saude Publica. 2012;28(10):1867-80.

Souza LZ, Rodrigues RGA, Oliveira DAD, Roman JL, Zabott MV, Pinto SB, et al. Soroprevalência de Toxoplasma gondii em gatos domiciliados em Palotina, Paraná, Brasil. Arq Cienc Vet Zool. 2017;20(3):123-6.

Sparkes AH, Bessant C, Cope K, Ellis SLH, Finka L, Halls $\mathrm{V}$ et al. ISFM Guidelines on Population Management and Welfare of Unowned Domestic Cats (Felis catus). J Feline Med Surg. 2013;15(9):811-7.

Stella JL, Croney CC. Environmental Aspects of domestic cat care and management: Implications for cat welfare. ScientificWorldJournal. 2016;2016:6296315.

Strickler BL, Shull EA. An owner survey of toys, activities, and behavior problems in indoor cats. J Vet Behav. 2014;9(5):207-14.
Sturgess K. Disease and Welfare. In: Rochlitz I. The Welfare of Cats. Dordrecht: Springer; 2007. 205 p.

Tortato MA, Oliveira TG, Almeida LB, Beisiegel BM. Avaliação do risco de extinção do gato-maracajá Leopardus wiedii (Schinz, 1821) no Brasil. Biodivers Bras. 2013;(1):76-83.

VanWormer E, Conrad PA, Miller MA, Melli AC, Carpenter TE, Mazet JA. Toxoplasma gondii, source to sea: Higher contribution of domestic felids to terrestrial parasite loading despite lower infection prevalence. Ecohealth. 2013;10(3):277-89.

Veissier I, Miele M. Animal welfare: towards transdisciplinarity - The European experience. Anim Prod Sci. 2014;54(9):1119-29.

Vigne JD, Guilaine J, Debue K, Haye L, Gérard P. Early taming of the cat in Cyprus. Science. 2004;304 (5668):259

Wald DM, Jacobson SK. Factors affecting student tolerance for free-roaming cats. Hum Dimens Wildl. 2013;18(4):263-78.

Wilson JL, Gruffydd-Jones TJ, Murray JK. Risk factors for road traffic accidents in cats up to age 12 months that were registered between 2010 and 2013 with the UK pet cat cohort ('Bristol Cats'). Vet Rec. 2017;180(8):195.

Yeates J, Yates D. Staying in or going out? The dilemma for cat welfare. Vet Rec. 2017;180(8):193-4.

Zanzani SA, Gazzonis AL, Scarpa P, Berrilli F, Manfredi MT. Intestinal parasites of owned dogs and cats from metropolitan and micropolitan areas: Prevalence, zoonotic risks, and pet owner awareness in northern Italy. Biomed Res Int. 2014;2014:696508.

Zito S, Vankan D, Bennett P, Paterson M, Phillips CJ. Cat ownership perception and caretaking explored in an internet survey of people associated with cats. PloS One. 2015;10(7):e0133293. 